\title{
“A ARTE DE ORGANIZAR PEDRAS". O SAKUTEIKI E A APLICAÇÃO PRÁTICA DA ESTÉTICA HEIAN NA JARDINAGEM
}

\author{
Maria do Carmo Oliveira da Silva Neta ${ }^{1}$
}

\begin{abstract}
Resumo: O presente artigo tem por finalidade analisar como a relação entre estética e hierarquia particulares ao período da história japonesa intitulado Heian, se refletem nos jardins da nobreza, tomando como base a obra Sakuteiki, um manual de jardinagem do século XI. Enquanto fonte principal analisada aqui, o Sakuteiki e sua autoria, bem como suas influências, referências e instruções, servirão como pontos de partida para delinear alguns conceitos religiosos e filosóficos acerca da construção dos jardins no período Heian. Esses conceitos compreendam a estrutura física do jardim, sua localização, os recursos naturais assim como influências religiosas e sociais, além da herança chinesa dentro da jardinagem japonesa do periodo.
\end{abstract}

Palavras-chave: História ambiental; História do Japão; Heian; Jardins; Estética.

Abstract: The present article aims to analyze how the relationship between aesthetic and hierarchy particular to Heian Japanese historical period, reflects itself in the nobility's gardens, according to the book Sakuteiki, a gardening manual from $11^{\text {th }}$ century. As the main source analyzed here, the Sakuteiki and its authorship, as well as its influences, references and instructions, will serve as starting points to describe some concepts about gardens construction in the Heian period. These concepts compreend the physical structure of the garden, its location, natural resources, as well as its religious and social influences, beyond the Chinese heritage inside the Japanese gardening in Heian period.

Keywords: Environmental History; Japanese History; Heian; Gardens; Aesthetic.

\section{Período Heian e sua relação com a natureza}

Dentro da cronologia histórica japonesa, os períodos são divididos de acordo com as grandes capitais ou os grandes líderes, diferentemente do ocidente, onde a História em muitos casos é comumente dividida em pré-história, idade antiga, idade média, idade moderna e contemporânea. Dito isso, o período Heian (平安時代) compreende o final do século VIII até o final do século XII, e possuiu uma imensa influência chinesa, em especial da China da dinastia $\mathrm{T}^{\prime}$ ang, ${ }^{2}$ nos âmbitos religioso, político e literário. Paradoxalmente, ao mesmo tempo em que foi o período com uma maior influência chinesa, foi também aquele no qual começou a desenvolver-se uma

\footnotetext{
${ }^{1}$ Graduanda em História na Universidade Federal de Pernambuco. Contato: Avenida Bom Jesus, Curado III - Jaboatão dos Guararapes - PE, Brasil. E-mail: mary.oliveirasilvan@gmail.com.

${ }^{2}$ Curiosamente, embora os chineses considerassem a dinastia Han (Séc. III a.C. - Séc. III d.C.) como seu grande referencial e baluarte cultural, ao ponto de nomear a etnia majoritária do país, os japoneses do período Heian tinham a China T’ang como seu grande ponto de referência cultural e política. Coincidentemente ou não, a dinastia T’ang (Séc. VII - Séc. X) entra para a história chinesa como o ápice do desenvolvimento artístico do país, uma era de ouro para a arte chinesa em seus mais diversos âmbitos, bem como o período Heian para o Japão.
} 
arte e uma estética essencialmente japonesas, rejeitando a partir daí, a influência chinesa nesse âmbito específico. O nome desse período provém de sua capital, Heian-Kyou (平 安京), cujo significado é “capital da paz e tranquilidade”, localizada onde hoje fica a cidade de Kyoto.

Acerca desse período, as principais fontes advêm da aristocracia, uma vez que os séculos X e XI foram o auge do poder centralizado da corte. Um dos principais responsáveis por essa concentração de poder na corte foi o clã Fujiwara (藤原氏). A ascensão desse clã se deu por meio de cargos de administração e regência próximos à família imperial, além do casamento de herdeiras Fujiwara com príncipes herdeiros, garantindo certa influência no filho resultante dessas uniões. Com uma estrutura política baseada na China T’ang, a corte japonesa da época possuía uma série de cargos burocratizados e concedidos aos nobres de acordo com seu grau de nobreza e competência, reafirmando o caráter hierárquico tão particular ao Japão..

Do ponto de vista religioso, temos duas religiões coexistindo no Japão: o Shintoísmo (religião tradicional japonesa, ligada à natureza e suas divindades) e o Budismo (religião de origem indiana introduzida no Japão no século $\mathrm{VI}^{3}$ ). Coexistindo pacificamente, as duas religiões serviram de suporte para a reafirmação do poder da corte, partindo do pressuposto que o Imperador era o filho de Amaterasu, ${ }^{4}$ principal divindade shintoísta, portanto teria legitimidade para governar. Já do ponto de vista budista, o mesmo Imperador seria o iluminado pelo Buda, conferindo assim um tom ainda mais divino à sua figura. Se levarmos em conta a proximidade dessa corte com a religiosidade, podemos notar uma proximidade também com a natureza. Essa aproximação da nobreza com o ambiente a partir da religião se dava por meio das peregrinações budistas, com destino a templos mais afastados da capital, onde convalesciam os doentes ou simplesmente apreciava-se a natureza em seus mais diversos âmbitos.

A natureza também se aproximava da aristocracia por meio da vestimenta. Numa corte extremamente hierarquizada, onde as vestes possuíam restrições quanto a

\footnotetext{
${ }^{3}$ Muito embora oficialmente o Budismo só tenha entrado no Japão por meio de uma embaixada vinda da Coreia, alguns historiadores acreditam que possa ter chegado um pouco antes no arquipélago japonês, por meio de piratas atuantes na costa. In: MATSUO, Kenji. A History of Japanese Buddhism. Global Oriental LTD, 2007.

${ }^{4}$ Deusa shintoísta que representava o sol, e principal deidade do panteão tradicional.
} 
cores, tecidos, texturas e comprimentos, temos uma ligação entre essas roupas e a natureza. Tal ligação se manifestava nas vestimentas com estampas sazonais, com combinações que lembrassem elementos típicos da estação vigente. Outra ligação é facilmente vista na associação feita entre as cores e estampas com a natureza, como no trecho: "Interessantes mesmo são as águas verdes profundas do [rio] Aoiro: podem até servir de tecido para os Secretários do Sexto Grau".

Dentro da tradição literária, não é incomum uma associação entre natureza e religião como forma de expressar um sentimento terreno. Muito embora a maior parte da produção poética seja budista, há também poemas que aludem à tradição shintoísta.

As folhas de sakaki

Da montanha Mimuro

Do Portal dos Deuses

Crescem em Profusão

À frente das divindades

Crescem em profusão. ${ }^{6}$

O período Heian foi também aquele em que foram escritas uma série de narrativas (conhecidas como Monogatari, 物語), bem como compêndios históricos, diários e compilações de textos poéticos, além de manuais da vida na corte. Um desses manuais é o Sakuteiki (作庭记), ponto de partida do presente trabalho.

Em algum ponto após o período Heian, um conjunto desses pergaminhos ficou em posse da família Maeda, de ricos lordes provinciais no que é hoje a Prefeitura de Ishikawa, no Japão central. A partir da família Maeda, cópias dos pergaminhos se espalharam por outras mãos, e uma cópia foi adquirida pela família Tanimura da cidade de Kanazawa. Posteriormente, entre os anos de 1779 e 1819 [...] os pergaminhos Tanimura foram utilizados na produção do Gunsho Ruijuu, uma coleção de literaturas históricas com mais de 1800 pergaminhos. [...] Não se sabe como era intitulado o Sakuteiki durante o período Heian; não há nenhum título nos pergaminhos Tanimura. $^{7}$

Não se sabe ao certo a data exata de escrita do Sakuteiki, bem como sua autoria. Uma vez que a cópia em posse do clã Tanimura não possuía título para o mesmo, Sakuteiki foi o nome dado por aqueles que compilaram o Gunsho Ruijuu. Uma

\footnotetext{
${ }^{5}$ SHONAGON, Sei. O Livro do Travesseiro. Trad. Geny Wakisaka, Junko Ota, Lica Hashimoto, Luiza Nana Yoshida e Madalena Hashimoto Cordaro. Editora 34, 2013, p. 94.

${ }^{6}$ Idem, p. 109.

${ }^{7}$ TAKEI, Jiro; KEANE, Marc P. Sakuteiki. Visions of the Japanese Garden: A Modern Translation of Japan's Gardening Classic. Tuttle Publishing, 2001, p. 6.
} 
vez que este último possui uma assinatura de Fujiwara no Yoshitsune ${ }^{8}$ (九条兼実), por muito tempo creditou-se a autoria do Sakuteiki a ele. No entanto, mais recentemente, estudos mais aprofundados apontam que Tachibana no Toshitsuna (橘俊綱) é que teria sido o verdadeiro autor da obra.

A família Tachibana seria uma das quatro maiores do período Heian, juntamente com os Fujiwara (藤原氏), os Heike (平家), e os Genji (源氏). ${ }^{10}$ Filho de um dos regentes imperiais, Fujiwara no Yorimichi ${ }^{11}$ (藤原頼通), Toshitsuna teria herdado de seu pai o interesse por belas residências, em especial por uma denominada Kayanoin, ${ }^{12}$ próxima ao palácio imperial, em Heian-Kyou. No Sakuteiki, o autor menciona ter visitado Kayanoin durante a construção de seus jardins, sendo esse um indício da autoria de Toshitsuna, dada sua ligação familiar com a residência. ${ }^{13}$

Toshitsuna assumiu um cargo administrativo na corte como Fushimi Shuri no Daibu (修理大夫), um tipo de oficial responsável por planejar e executar a construção de residências na capital, bem como ordenar reparos e reformas. Sendo assim, ele era responsável pela construção e reforma de inúmeros jardins, uma vez que permaneceu no cargo por cerca de 24 anos. ${ }^{14}$ Tendo construído ao longo de todos esses anos uma grande reputação enquanto arquiteto de jardins, Toshitsuna teria escrito o Sakuteiki como forma de condensar todo seu conhecimento acerca da temática.

\section{Estilos residenciais e construção de jardins}

Tendo em vista que Heian-Kyou era uma capital completamente planejada, haviam inúmeras regras em relação à construção e reforma das residências, o que explica a importância da função desempenhada por Toshitsuna. $\mathrm{O}$ estilo residencial que imperava entre a aristocracia da época era denominado Shinden-zukuri (寝殿造),

\footnotetext{
${ }^{8}$ Teria vivido entre 1169 a 1206 , foi um dos regentes de seu clã na corte.

${ }^{9}$ Teria vivido entre 1028 e 1094 .

${ }^{10} \mathrm{O}$ clã Heike, também era conhecido como clã Taira, e o clã Genji era conhecido por Minamoto. Os nomes mudam de acordo com a leitura dada aos ideogramas de seus nomes.

${ }^{11}$ Teria vivido entre 992 e 1074, filho do maior líder da história dos Fujiwara, Fujiwara no Michinaga, e teria sido regente do Imperador Go Ichijou a partir de seus 25 anos, tendo assim um enorme prestígio dentro da corte.

${ }^{12}$ Não se sabe ao certo qual seria a grafia correta dos caracteres que compõem Kayanoin, sendo assim existem duas grafias possíveis: 寝殿造 ou 高陽院.

13 TAKEI, Jiro; KEANE, Marc P. Sakuteiki. Visions of the Japanese Garden. Op. cit., p. 7.

${ }^{14}$ Ibidem.
} 
profundamente inspirado nas residências T'ang. Uma vez que o principal material para essas construções era papel e madeira, havia um risco sempre iminente de incêndios, o que demandava reparações quase que constantes nessas residências. Um outro detalhe acerca desse tipo de construção que virá a ser retomado mais à frente, é seu posicionamento em relação ao jardim. A construção dessas residências se orienta a partir do mesmo, principalmente na escolha do terreno.

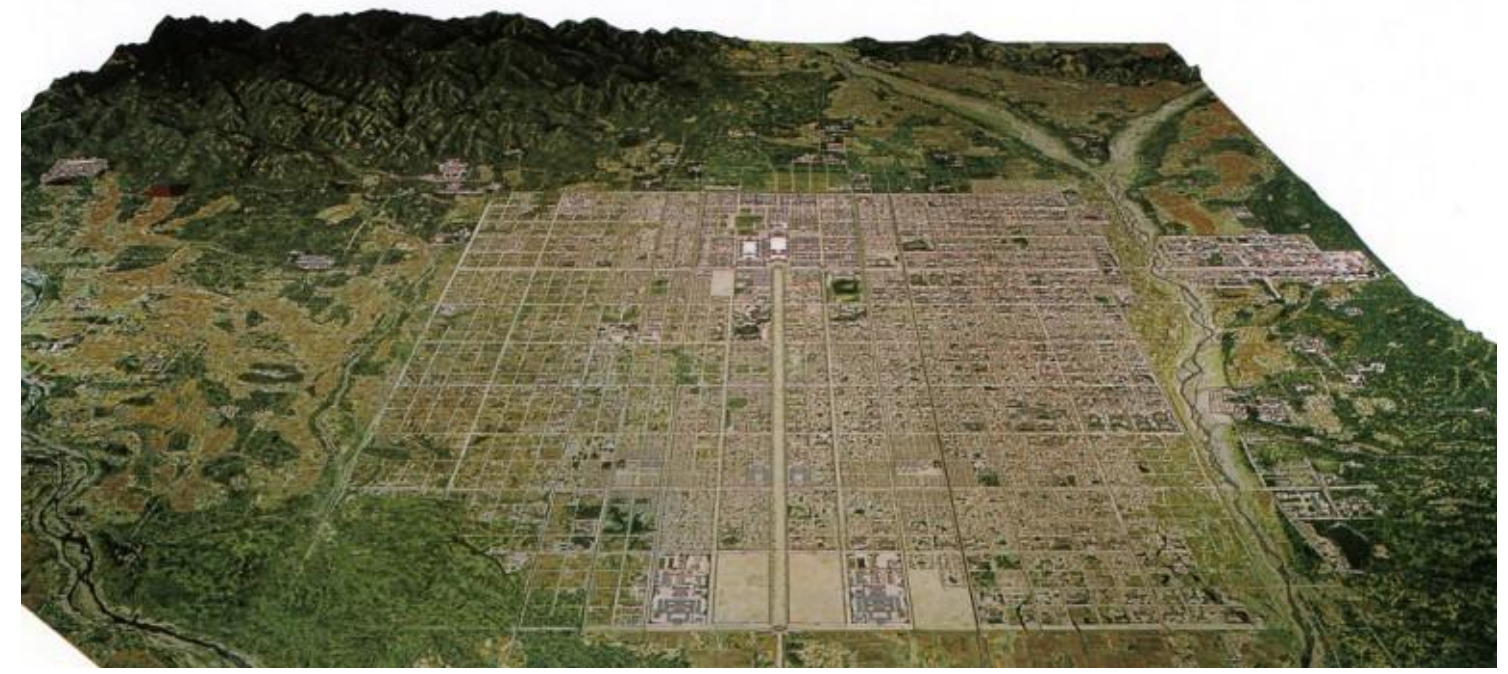

Figura 1. Mapa topográfico de Heian-Kyou. ${ }^{15}$

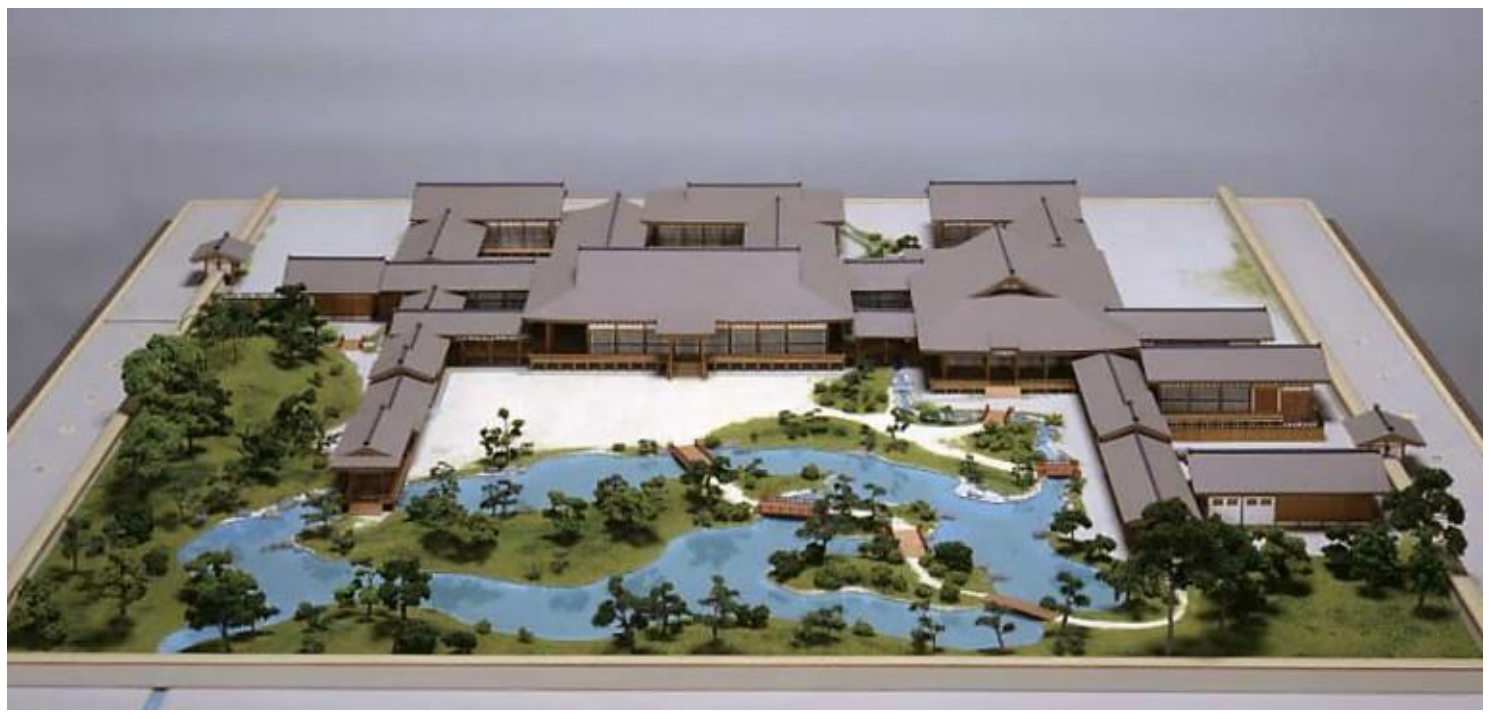

Figura 2. Modelo em miniatura de uma residência no estilo Shinden. ${ }^{16}$

${ }^{15}$ In: <http://www.orjach.org/module/growth-of-cities/> Acessado em: 05/12/2017.

16 A residência reproduzida no modelo é a Higashi Sanjo Dono (東三条殿), um dos palacetes do clã Fujiwara. Nota-se as enormes proporções do jardim em relação à residência, em especial do lago, que deveria ter proporções suficientes para acomodar pequenas embarcações com músicos em dias de festa, 
No que diz respeito à obra, trata-se de um manual de jardinagem extremamente pragmático. Divide-se em textos curtos e diretos, com regras e orientações específicas. O livro traz também um lado teórico, mesclando as religiões vigentes à época (Shintoísmo e Budismo) com tradições chinesas, tais quais a geomancia e o taoísmo.

Selecione muitos lugares dentro da propriedade de acordo com a forma da terra e dos lagos, e crie uma atmosfera sutil, se refletindo de novo e de novo nas memórias da natureza selvagem.

Quando criar um jardim, deixe o trabalho excepcional dos mestres jardineiros anteriores ser o seu guia. Atente para os desejos do mestre da casa, ainda que atente também para o seu próprio gosto.

Visualize as paisagens famosas de nosso país e compreenda seus pontos mais interessantes. Recrie a essência dessas cenas no jardim, mas apenas interpretativamente, não literalmente. ${ }^{17}$

\section{Influências religiosas e culturais dentro do Sakuteiki}

A frase que inicia o Sakuteiki, "Ishi wo taten koto", ${ }_{18}^{18}$ cujo significado é "a arte de organizar pedras", diz muito acerca da importância das mesmas dentro do jardim. Alguns autores vão apontar a utilização das pedras em espaços sagrados desde os tempos antigos, com preferência para pedras com "formatos arredondados ou aparência naturalmente ereta", ${ }^{19}$ denominadas Iwakura (岩倉). Acreditava-se então, que por meio dessas pedras, os deuses poderiam fazer intermédio com o mundo humano, visitando a terra e espalhando bênçãos. A ligação das pedras com o sagrado permanece mesmo quando começam a ser utilizadas dentro da jardinagem. À sua importância de base shintoísta, somam-se os significados acrescidos pelo Budismo e pela Geomancia no período Heian.

A Geomancia, arte mística originária da China, tem como objetivo a adivinhação e organização do espaço segundo as energias da terra, e é popularmente conhecida como feng shui (風水). Quando aplicada ao contexto da jardinagem no Sakuteiki, ela oferece uma forma de interferir com a natureza de maneira que se equilibrem as

bem como ilhas artificiais. In: <http://www.orjach.org/module/growth-of-cities/> Acessado em 05/12/2017.

${ }^{17}$ TAKEI, Jiro; KEANE, Marc P. Sakuteiki. Visions of the Japanese Garden. Op. cit., p. 153.

${ }^{18}$ Como explicam os tradutores da obra, a frase “石をたてんこと” pode ser traduzida de maneira literal como "problemas de organizar pedras", mas para o contexto era mais adequado utilizar o termo "arte". Idem, p. 3.

${ }^{19}$ Idem, p. 4 
energias e as consequências de se interferir no meio ambiente sejam minimizadas. Sendo assim, o autor a utiliza muito pragmaticamente determinando onde e quando deve-se inserir uma pedra ou um determinado tipo de planta. ${ }^{20}$

Quando uma pedra oriunda das montanhas ou do leito de um rio é posta da maneira das deidades, esta vai se tornar uma pedra demoníaca. Existem muitos casos de problemas decorrentes de se fazer isso por todo o país. ${ }^{21}$

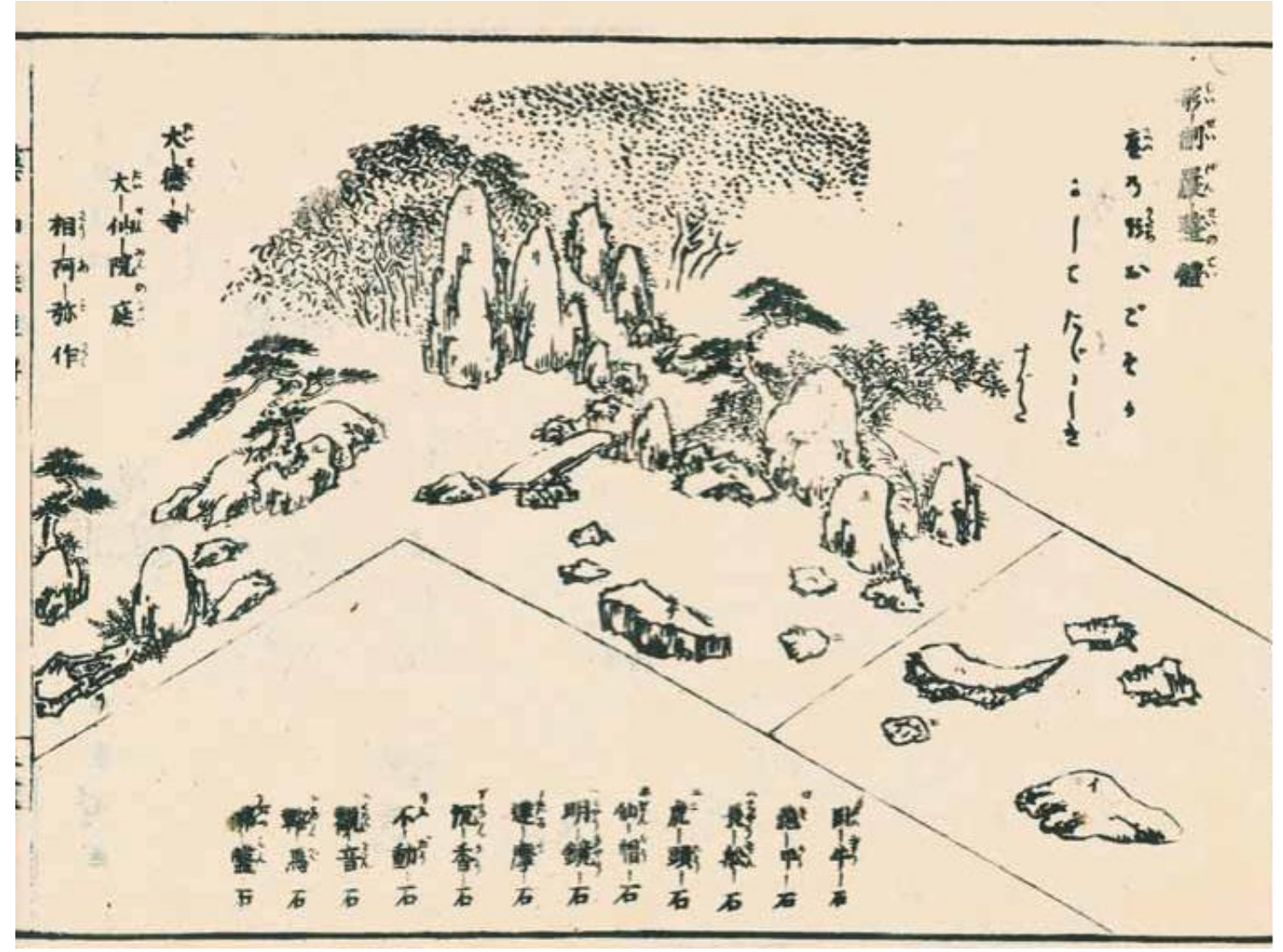

Figura 3. Excerto do manual Tsukiyama Teizoden, listando tipos de pedras e seus nomes. ${ }^{22}$

\footnotetext{
${ }^{20}$ Vale salientar que dentro do jardim Heian absolutamente todos os componentes são milimetricamente calculados quanto à sua posição. E que muito embora a Geomancia seja de origem chinesa, sua aplicação nos jardins japoneses seguiu não apenas sua lógica própria, como também foi utilizada para reafirmar as lógicas shintoísta, taoísta e budista de organização do jardim.

${ }^{21}$ Idem, p. 191.

${ }^{22}$ Muito embora o manual em questão tenha sido publicado em 1745 , mostra como as pedras permanecem importantes dentro da arte da jardinagem, e que a importância dada às mesmas pelo autor do Sakuteiki não se liga apenas a gosto pessoal. In: MANSFIELD, Stephen. Japanese Stone Gardens: origin, meaning, form. Tuttle Publishing, 2009, p. 26.
} 
Acerca do Budismo, não há praticamente nenhuma menção dentro do Sakuteiki, o que não implica dizer que não haja uma influência do mesmo na obra, uma vez que o manuscrito Gion Shouja, escrito por um monge budista e citado pelo autor do Sakuteiki como referência de pesquisa. ${ }^{23}$ Outras influências se dão por meio da construção de cachoeiras (ligadas a divindades budistas) e também por meio das pedras, no que diz respeito às pedras que representam a trindade budista.

Todas as cachoeiras são certamente expressões de uma Trindade Budista: as duas pedras de flanco, à direita e à esquerda da pedra dominante, provavelmente representam os criados do Buda... Para contemplar minha forma não é preciso conhecer a forma do Shoukoku Douji. ${ }^{24}$

Uma vez que a nobreza Heian se reflete no conceito de mono no aware, traduzido como "qualidade emocional das coisas", ${ }^{25}$ vemos que a estética e o sentimentalismo caminham lado a lado, fazendo da beleza um sinônimo de sensibilidade emocional. Um bom exemplo da mescla entre as tradições chinesas e as convicções dessa nobreza se encontra no plantio de duas árvores floríferas: a Sakura (桜 ) e a Tachibana (橘).

No caso do salão de estado imperial, Shishinden, duas árvores eram plantadas na Corte Sul por razões especificamente simbólicas, uma em cada lado das escadas que levavam ao hall principal. No oeste ficava uma árvore cítrica chamada tachibana, e no lesta ficava uma cerejeira, sakura. A sempre verde árvore cítrica simbolizava as coisas eternas, enquanto a decídua cerejeira evocava a imagem de coisas evanescentes. Yang e Yin dentro do jardim. ${ }^{26}$

Outro conceito da nobreza Heian que vai ser colocado de maneira muito enfática dentro do Sakuteiki é o da hierarquia. Numa corte pautada pela estética e moldada por regras e restrições ligadas aos cargos desempenhados ou à importância e

\footnotetext{
23 "A fim de se criar a solenidade necessária na residência de um nobre, construa montanhas no jardim como aquelas vistas no texto ilustrado de gion". In: TAKEI, Jiro; KEANE, Marc P. Sakuteiki. Visions of the Japanese Garden. Op. cit., p. 94.

${ }^{24}$ TAKEI, Jiro; KEANE, Marc P. Sakuteiki, Visions of the Japanese Garden: A Modern Translation of Japan's Gardening Classic. Tuttle Publishing, 2001, p. 107.

NITSCHKE, Günter. Japanese Gardens: Right angle and natural form. Taschen, 2003, p. 53.

${ }^{26}$ A utilização dessas árvores como forma de representar o conceito de YinYang presente na cultura chinesa, em especial nas tradições taoístas e geomancistas, denota quanto da cultura dessa corte ainda estava ligada aos preceitos chineses. In: TAKEI, Jiro; KEANE, Marc P. Sakuteiki, Visions of the Japanese Garden: A Modern Translation of Japan's Gardening Classic. Tuttle Publishing, 2001, p. 21
} 
influência política, ${ }^{27}$ uma vez que as residências nobres eram construídas ao redor dos jardins (o que evidencia assim sua importância), havia uma enorme rigidez no que era considerado aceitável ou inaceitável dentro do jardim. Essa rigidez perpassa não apenas a organização e disposição dos jardins, como também a fauna e flora, dadas as grandes proporções que esses jardins costumavam possuir.

Tabela 1. Exemplos de categorias vegetais mencionadas no Sakuteiki ${ }^{28}$

\begin{tabular}{|c|c|c|c|}
\hline Nome & Caractere & Nome científico & Tipo de vegetal \\
\hline Tachibana & 橘 & Citrus tachibana & $\begin{array}{l}\text { Árvore } \\
\text { intermitente }\end{array}$ \\
\hline Momi & 樅 & Aibes firma & Árvore conífera \\
\hline Yanagi & 柳 & Salix sp. & Árvore sazonal \\
\hline Sakura & 桜 & Prunus sp. & Árvore florífera \\
\hline Momo & 桃 & Prunus pérsica & Árvore frutífera \\
\hline Sakaki & 榊 & Cleyera japonica & Arbusto \\
\hline Kuredake & 呉竹 & $\begin{array}{l}\text { Phyllostachys } \\
\text { nigra }\end{array}$ & Bambu \\
\hline Shirokiku & 白菊 & $\begin{array}{l}\text { Chrysanthemum } \\
\text { sp. }\end{array}$ & Herbácea \\
\hline Shiba & 芝 & Zoysia japonica & Gramínea \\
\hline Hasu & 蓮 & $\begin{array}{l}\text { Nelumbo } \\
\text { nucifera }\end{array}$ & Planta aquática \\
\hline Fuji & 藤 & Wisteria sp. & Vinácea \\
\hline
\end{tabular}

${ }^{27}$ É importante lembrar que a importância e influência de um nobre na corte desse período está profundamente ligada ao nascimento e descendência, contribuindo para uma mobilidade social (dentro da nobreza) extremamente limitada, o que se estende aos cargos administrativos.

${ }^{28}$ TAKEI, Jiro; KEANE, Marc P. Sakuteiki, Visions of the Japanese Garden: A Modern Translation of Japan's Gardening Classic. Tuttle Publishing, 2001, p. 233-235. 


\section{Natureza e Literatura}

Embora seja um manual prático para a construção, reforma e organização de jardins, o Sakuteiki traz muitas das características religiosas, bem como culturais da nobreza Heian dentro da arte da jardinagem. Dentro da literatura clássica do período vemos também inúmeras menções a jardins, além de menções a plantas citadas no Sakuteiki como sendo belas ou nobres, o que reafirma a ideia de que os conceitos contidos no manual não seguem uma lógica estritamente ligada ao gosto pessoal, mas sim aos preceitos difundidos naquela sociedade. Um claro exemplo dessas referências e que reafirma a importância da conexão entre nobreza e natureza se encontra na obra $O$ Conto de Genji. Duas das principais personagens femininas são conhecidas apenas pelo nome das cortes onde residem, as quais por sua vez recebem nomes de flores reverenciadas nos jardins da época. As personagens são as damas Kiritsubo (桐壱) e

\section{Fujitsubo (富士壳). ${ }^{29}$}

Outro exemplo na literatura se centra no Sarashina Nikki (更級日記), diário de uma dama da corte do século XI ${ }^{30}$ no qual sua autora detalha peregrinações a templos budistas afastados da capital, bem como suas viagens acompanhando o pai, que trabalhou como administrador provincial. Sua obra é repleta de descrições acerca da natureza e suas impressões acerca da mesma.

Dentre os diários, outro de muita fama é o Livro do Travesseiro, que menciona cerca de 121 tipos de vegetais ao longo de seu texto, além de muitas cenas de suas narrativas se passarem em jardins, demonstrando assim que o mesmo era um espaço frequentado pela nobreza com regularidade. Essa frequente utilização do espaço dos jardins pela aristocracia explica o porquê do Sakuteiki destrinchar tanto a arte de

\footnotetext{
${ }^{29}$ Segundo Shirane, há uma vasta gama de personagens femininas no Conto de Genji que receberam nomes de plantas ornamentais ou de elementos da natureza. In: SHIRANE, Haruo. Japan and the culture of the Four Seasons: nature, literature and the arts. Columbia University Press, 2012, p. 1.

${ }^{30}$ Não se sabe ao certo muito sobre essa dama, nem mesmo seu nome verdadeiro. Teria nascido no ano 1008 e possuía parentesco com a autora de outro diário famoso do período: o Kagerou Nikki.
} 
construir jardins de maneira profundamente detalhada, e também o porquê do mesmo refletir a hierarquia dessa sociedade.

\section{Considerações finais}

A partir do que foi exposto neste trabalho, é possível perceber, então, que há uma relação dentro do período Heian entre a nobreza e a natureza, e essa relação perpassa não apenas o caráter estético, mas também o caráter religioso, artístico e literário. E dentro de uma aristocracia tão profundamente hierarquizada e meticulosamente organizada (o que se reflete em sua arquitetura), há a reflexão dos principais conceitos dessa sociedade na arte da jardinagem, fazendo do jardim a expressão máxima da junção entre aristocracia e natureza.

Sendo assim, vê-se no Sakuteiki uma obra que condensa os principais conceitos acerca da arte da jardinagem no período Heian, bem como suas referências religiosas, estéticas e as influências maciças da China T'ang no que diz respeito à organização e orientação do jardim.

\section{Referências bibliográficas}

KATO, Shuichi. A History of Japanese Literature: The First Thousand Years. Paul Norbury Publications LTD, 1979. Vol. 1

MANSFIELD, Stephen. Japanese Stone Gardens: origin, meaning, form. Tuttle Publishing, 2009.

MATSUO, Kenji. A History of Japanese Buddhism. Global Oriental LTD, 2007

MEHTA, Geeta K.; TADA, Kimie; MURATA, Noboru. Japanese Gardens: tranquility, simplicity, harmony. Tuttle Publishing, 2008.

NITSCHKE, Günter. Japanese Gardens: Right angle and natural form. Taschen, 2003.

SEIDENSTICKER, Edward G. (1921-2007). The Tale of Genji. 2 vols. New York: Alfred A. Knopf, 1976

SHIRANE, Haruo. Japan and the culture of the Four Seasons: nature, literature and the arts. Columbia University Press, 2012.

SHIVELY, Donald H.; McCUllOUGH, William H. The Cambridge History of Japan. Cambridge: Cambridge University Press, 1999. Volume 2: The Heian Japan.

SHONAGON, Sei. O Livro do Travesseiro. Trad. Geny Wakisaka, Junko Ota, Lica Hashimoto, Luiza Nana Yoshida e Madalena Hashimoto Cordaro. Editora 34, 2013. 
TAKEI, Jiro; KEANE, Marc P. Sakuteiki. Visions of the Japanese Garden: A Modern Translation of Japan's Gardening Classic. Tuttle Publishing, 2001.

WORSTER, Donald. "Para fazer história ambiental". Revista Estudos Históricos, Rio de Janeiro, v. 4, n. 8, p. 198-215, dez. 1991. 